Supporting Information

\title{
Highly Invisible Photonic Crystal Patterns Encrypted in Inverse Opaline Macroporous Polyurethane Film for Anti-counterfeiting Applications
}

Ke Chen, $†$ Yixin Zhang, $†$ Jianping Ge*

(† These authors contributed equally to this work)

School of Chemistry and Molecular Engineering, Shanghai Key Laboratory of Green

Chemistry and Chemical Processes, East China Normal University, Shanghai, 200062, China.

E-mail: jpge@chem.ecnu.edu.cn

\section{Contents}

1. Transmission spectrum of the original IOM-PU film .............................. S-2

2. Transmission spectrum of the heated IOM-PU film ............................ S-2

3. XRD patterns of the heated IOM-PU film ........................................ S-3

4. Tensile stress test of the heated IOM-PU film .................................... S-3

5. SEM image of IOM-PU film infiltrated with PEGDA …....................... S-4

6. Reflection spectra of the wet-heated IOM-PU film in soaking and drying ........... S-4

7. Reflection spectra of the IOM-PU film soaked by EG-EtOH inks .................. S-5

8. Small ink droplets on the IOM-PU film ........................................ S-5

9. Triangle pattern revealed by EtOH- $\mathrm{H}_{2} \mathrm{O}$ solutions ................................... S-6

10. Reflection spectra changes for the using of different $\mathrm{EtOH}-\mathrm{H}_{2} \mathrm{O}$ developing liquids .. S-7

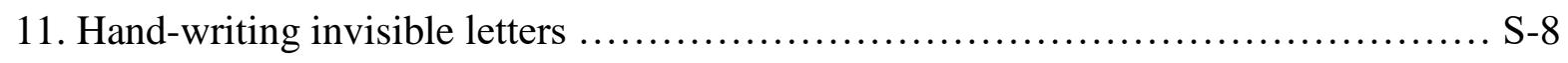

12. Contact angles on heated IOM-PU film ........................................ S-9

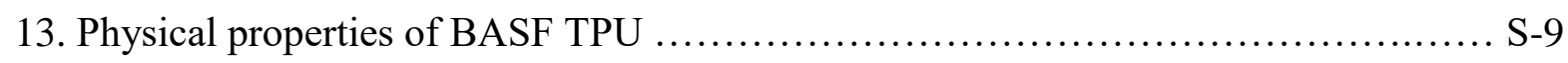




\section{Transmission spectrum of the original IOM-PU film.}

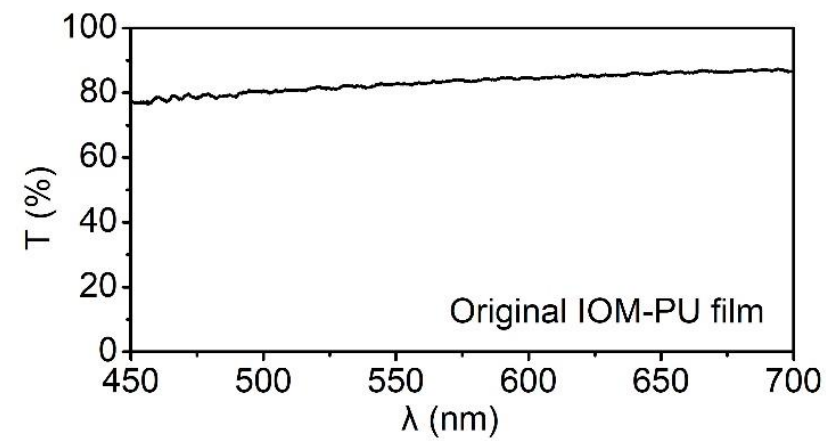

Figure S1. Transmission spectrum of the original IOM-PU film.

\section{Transmission spectrum of the heated IOM-PU film.}
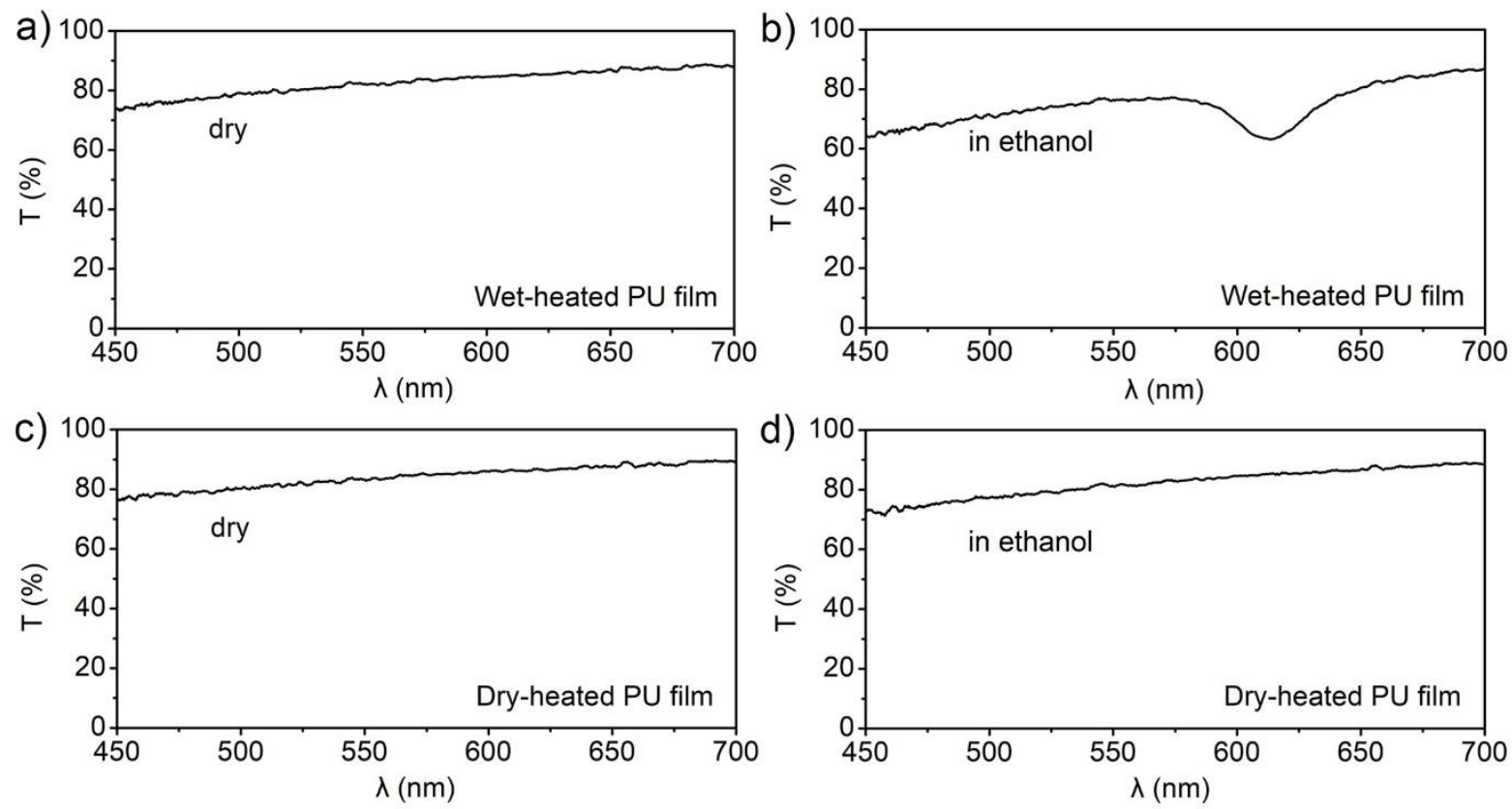

Figure S2. Transmission spectra for $(\mathrm{a}, \mathrm{b})$ the wet-heated and (c, d) the dry-heated IOM-PU films in the dry state and soaking state (ethanol). 
3. XRD patterns of the heated IOM-PU film.

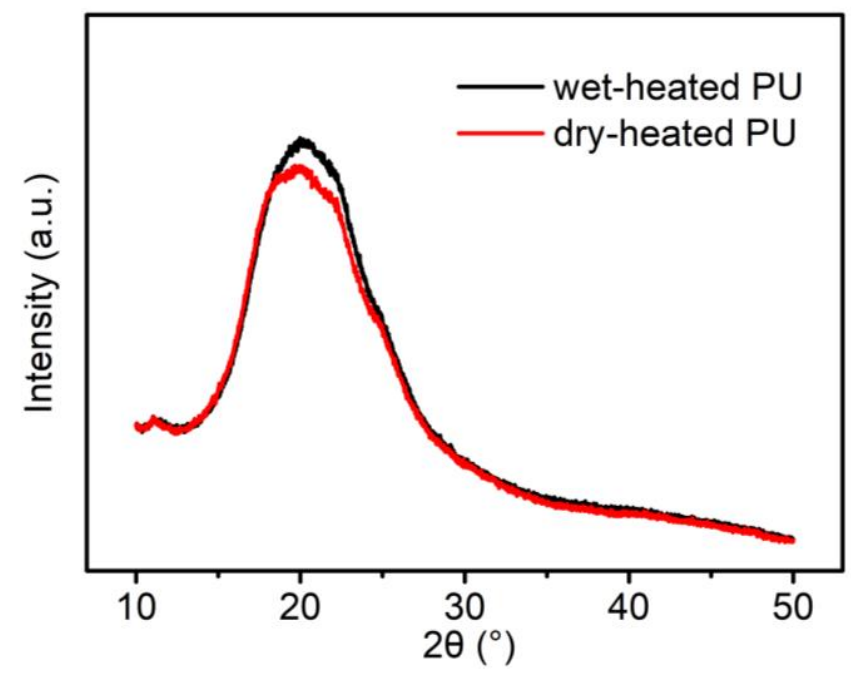

Figure S3. XRD patterns of the wet- and dry-heated PU films.

4. Tensile stress test of the heated IOM-PU film.

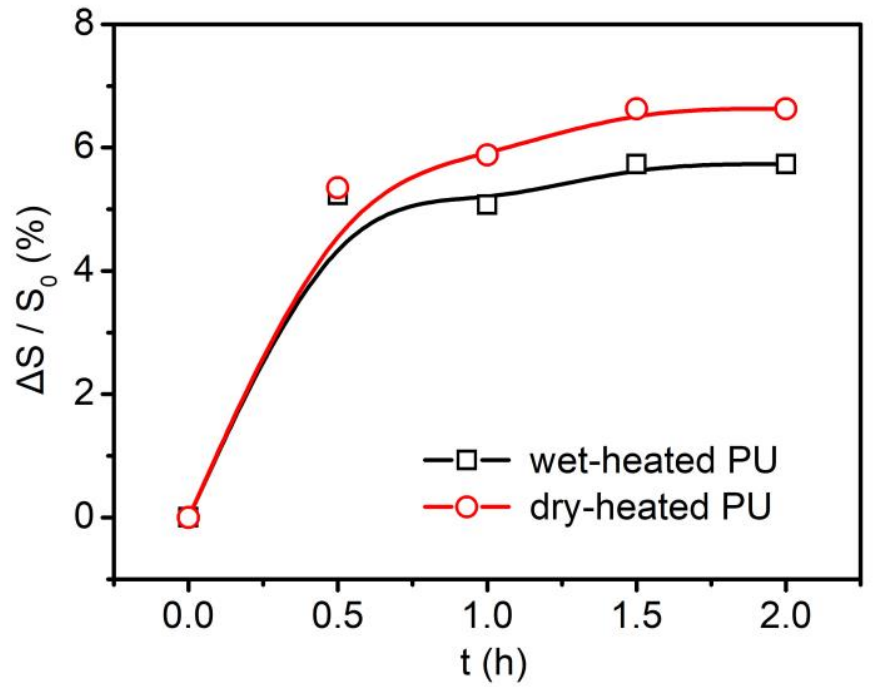

Figure S4. Swelling ratio of the wet- and dry-heated PU films in ethanol gradually increases along with the time. The ratio is calculated by the increasing percentage of the area of a thin PU film. 


\section{SEM image of IOM-PU film infiltrated with PEGDA.}

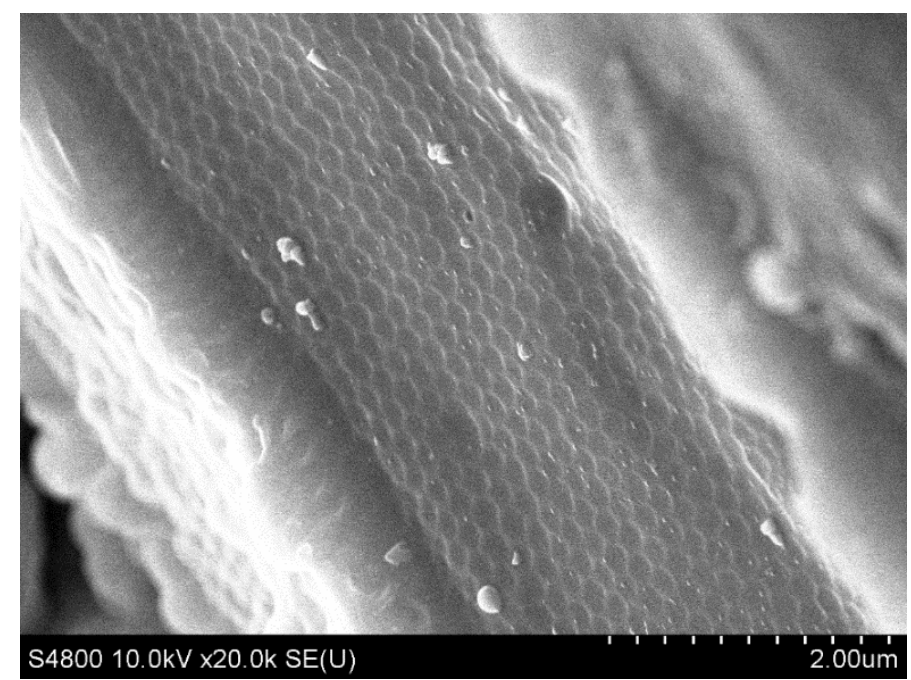

Figure S5. Cross-sectional SEM image of a polyethylene glycol diacrylate (PEGDA) soaked IOM-PU film after UV curing proves the recovery of the ordered IOM structure

\section{Reflection spectra of the wet-heated IOM-PU film in soaking and drying.}
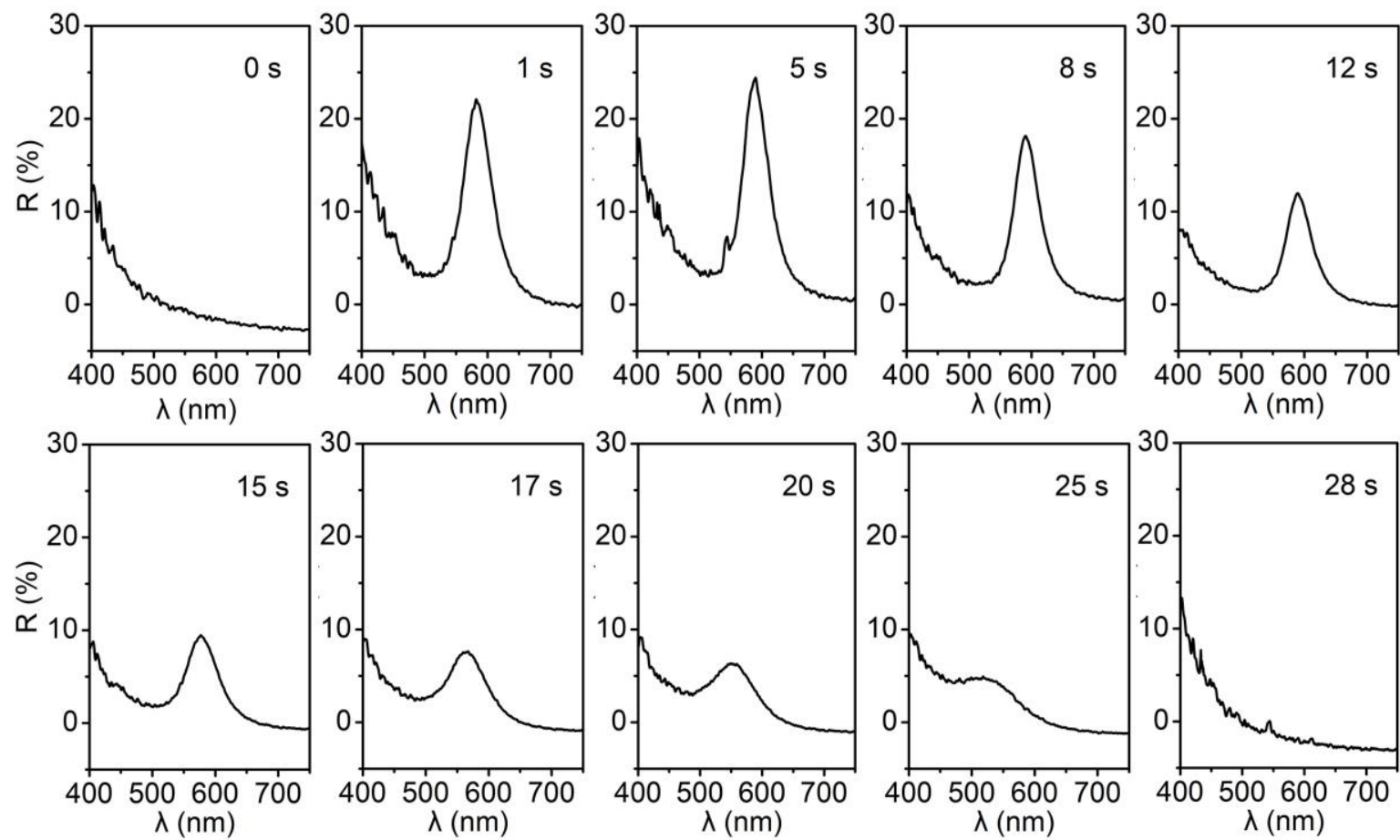

Figure S6. Reflection spectra of the wet-heated IOM-PU in Figure 4f. Reflection spectra of the dry-heated PU are flat base lines with no reflection at any wavelengths. 
7. Reflection spectra of the IOM-PU film soaked by EG-EtOH inks.
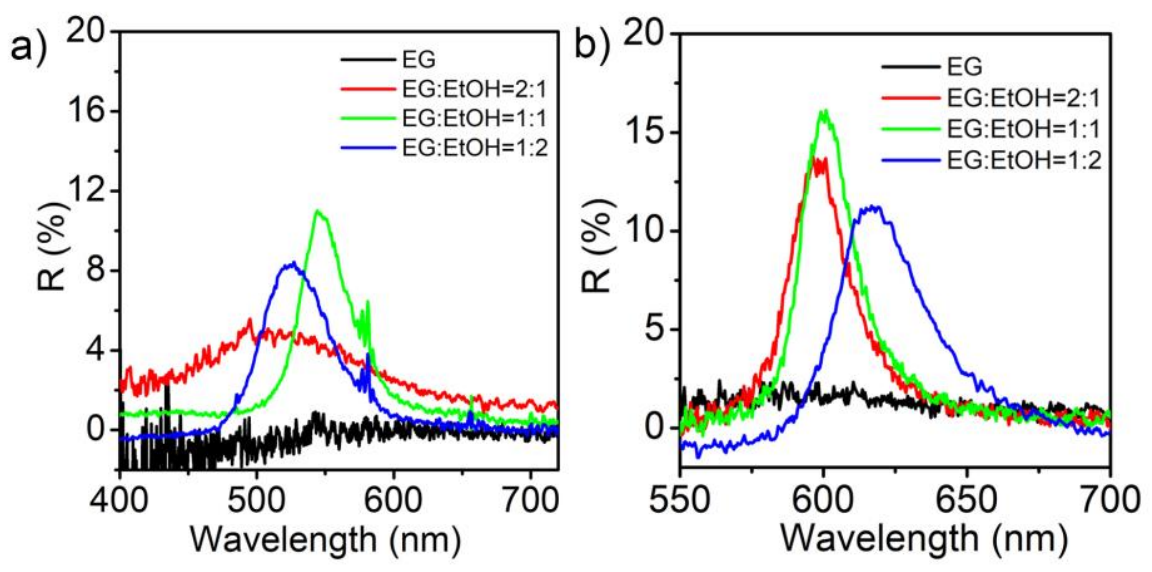

Figure S7. Reflection spectra of the IOM-PU film soaked by EG-EtOH inks (a) before and (b) after heating at $90^{\circ} \mathrm{C}$ for $1 \mathrm{~min}$

8. Small ink droplets on the IOM-PU film.

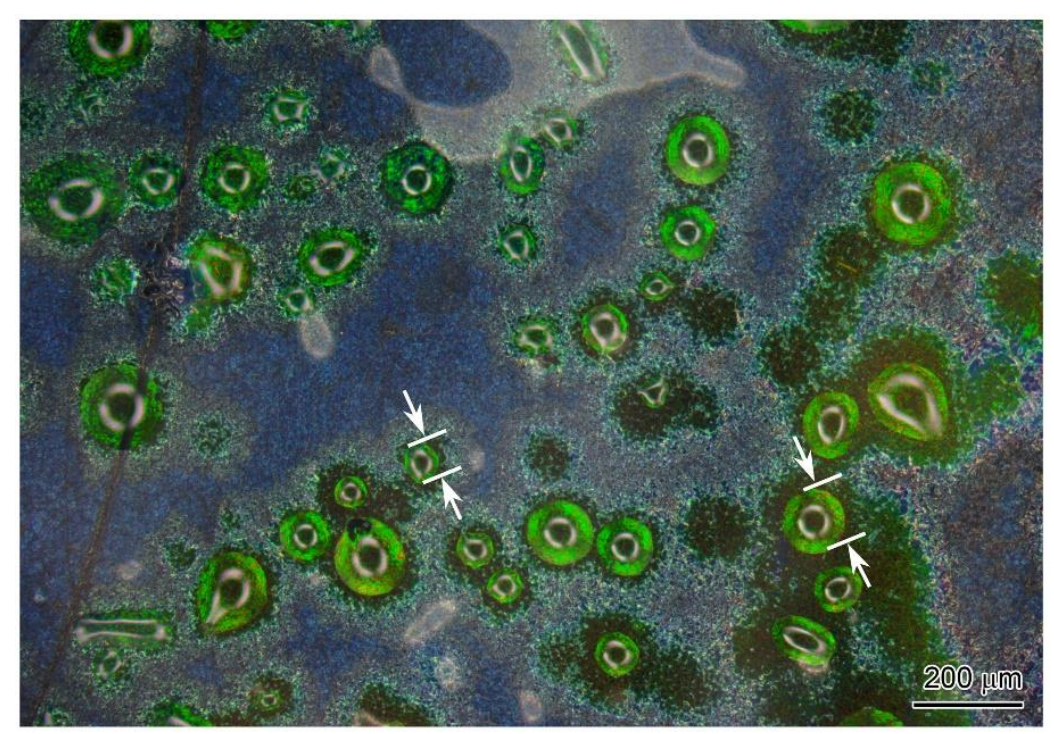

Figure S8. Optical microscope image of ink droplets on the collapsed IOM-PU film prepared by spraying. 
9. Triangle patterns revealed by EtOH- $\mathrm{H}_{2} \mathrm{O}$ solutions.
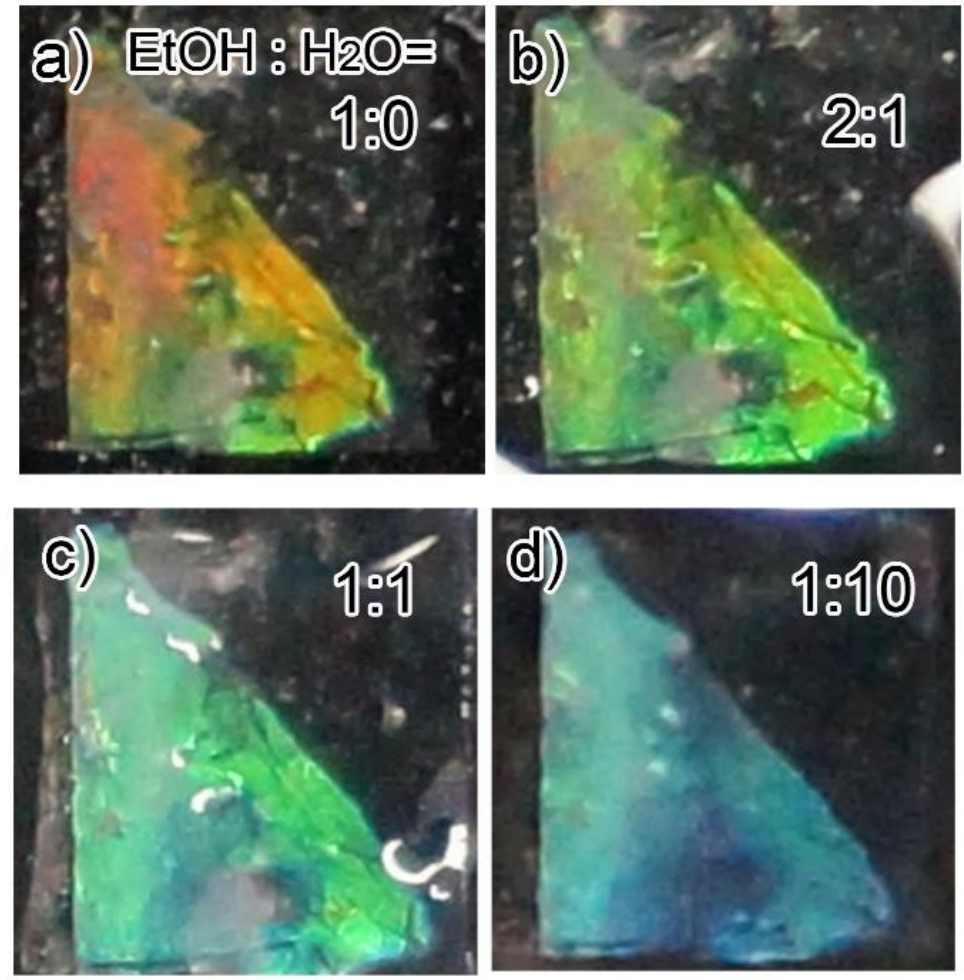

Figure S9. Digital photos of triangle pattern revealed by EtOH- $\mathrm{H}_{2} \mathrm{O}$ solutions with ratios of (a) 1:0, (b) $2: 1$, (c) $1: 1$, and (d) $1: 10$. 
10. Reflection spectra changes for the using of different EtOH-H2O developing liquids.
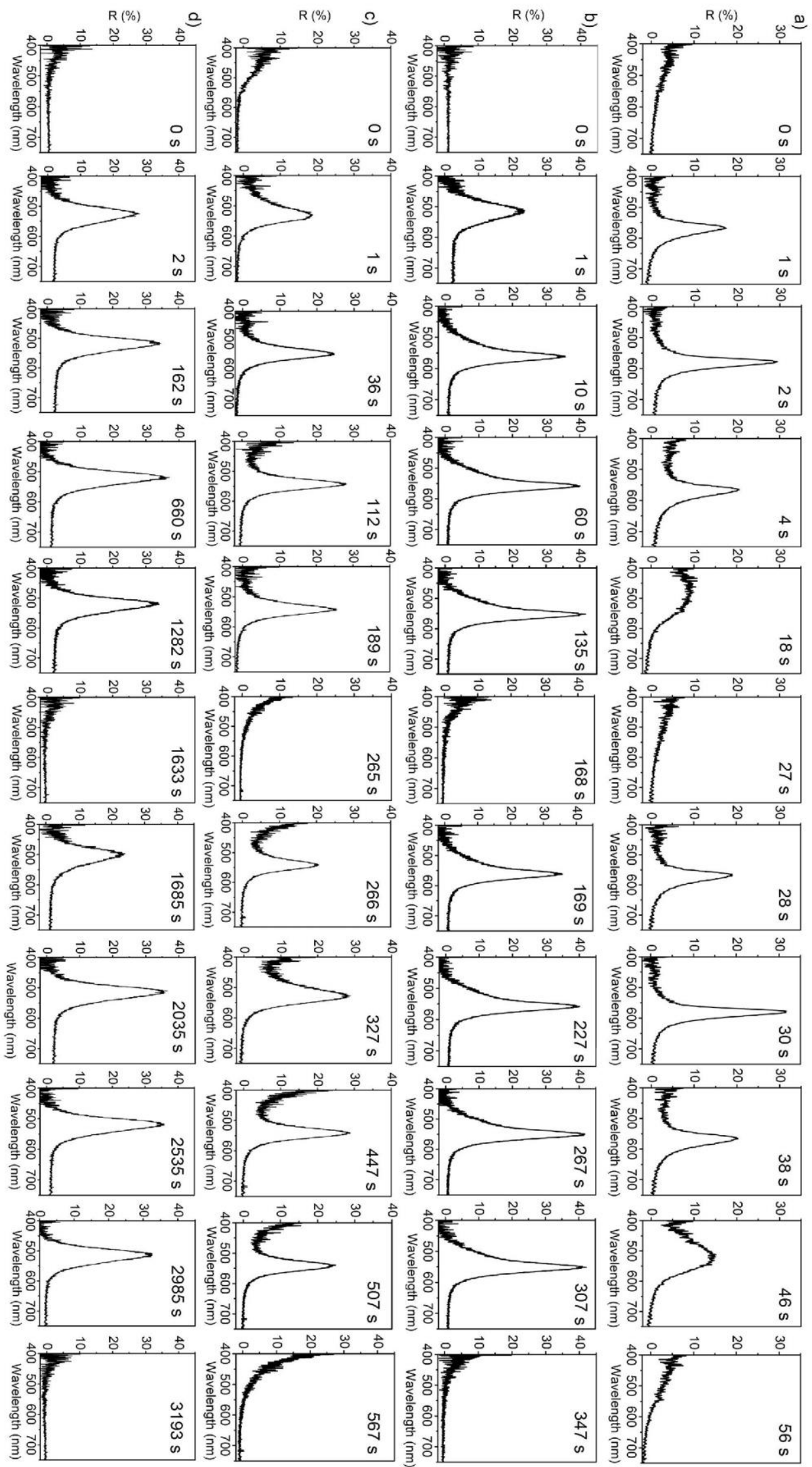

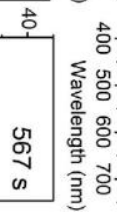
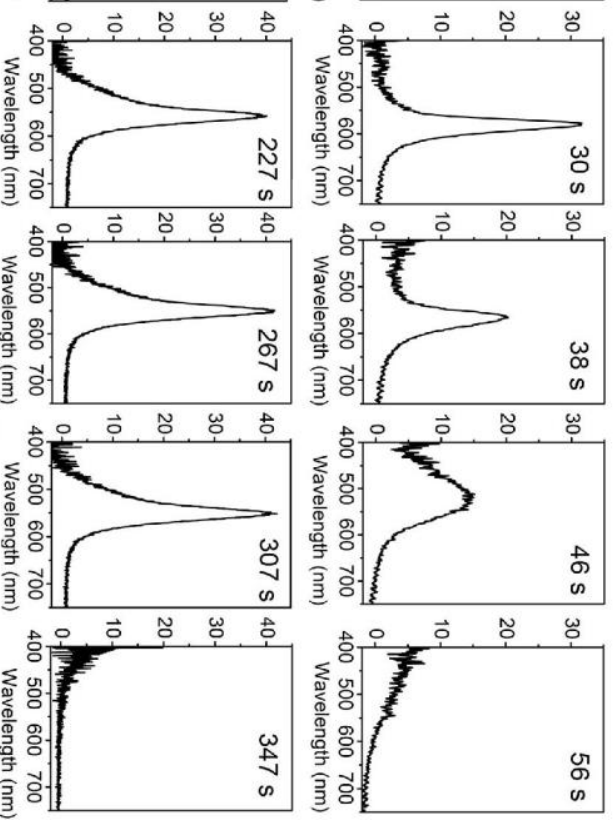
Figure S10. Time evolution reflection spectra of the wet-heated IOM-PU film soaked by different $\mathrm{EtOH}-\mathrm{H} 2 \mathrm{O}$ liquids. The ratio of $\mathrm{EtOH}$ and $\mathrm{H} 2 \mathrm{O}$ were set to be (a) 1:0, (b) 2:1, (c) 1:1, and (d) $1: 10$.

11. Hand-writing invisible letters.
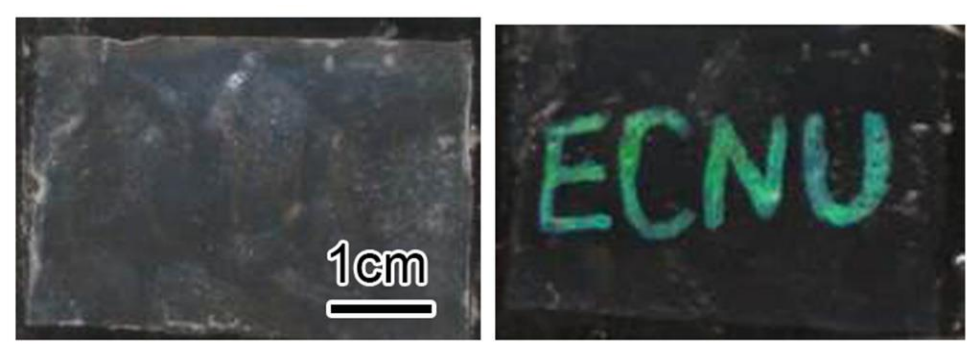

Figure S11. Invisible PC letters written by hand. 


\section{Contact angles on heated IOM-PU film.}

Table S1. Contact angles of EtOH- $\mathrm{H}_{2} \mathrm{O}$ mixtures on the surface of the wet- and dry-heated IOM-PU films.

\begin{tabular}{llllll}
\hline $\mathrm{H}_{2} \mathrm{O}$ in mixture / \% & 100 & 80 & 60 & 40 & 0 \\
\hline Wet-heated IOM-PU / & 90 & 53.5 & 26 & 11 & 1 \\
Dry-heated IOM-PU / & 97.5 & 75 & 53 & 40 & 3 \\
\hline
\end{tabular}

\section{Physical properties of BASF TPU.}

Table S2. Physical properties of the polyether-based polyurethane used in this work. (copied datasheet of Elastollan 1190A from BASF)

\begin{tabular}{|c|c|c|c|}
\hline Typical Properties of Elastollan ${ }^{\circledR}$ & ASTM Test Method & Units & Typical Values \\
\hline \multicolumn{4}{|c|}{$\begin{array}{l}\text { All the physical properties reported here are measured on injection molded samples. Properties of sheet } \\
\text { or film samples of this product are also available upon request. }\end{array}$} \\
\hline Specific Gravity & ASTM D 792 & $\mathrm{~g} / \mathrm{cm}^{3}$ & 1.13 \\
\hline Shore Hardness & ASTM D 2240 & Shore A or D & $90 \mathrm{~A}$ \\
\hline Taber Abrasion & ASTM D 1044 & mg loss & 45 \\
\hline DIN Abrasion & DIN 53516 & $\mathrm{~mm}^{3}$ loss & 25 \\
\hline E-Modulus & ASTM D 412 & psi & 4500 \\
\hline Flexural Modulus & ASTM D 790 & psi & 4200 \\
\hline Tensile Strength & ASTM D 412 & psi & 5400 \\
\hline Tensile Stress at $100 \%$ Elongation & ASTM D 412 & psi & 1800 \\
\hline Tensile Stress at $300 \%$ Elongation & ASTM D 412 & psi & 4000 \\
\hline Ultimate Elongation & ASTM D 412 & $\%$ & 460 \\
\hline Tear Strength & ASTM D 624, Die C & $\mathrm{lb} /$ in & 730 \\
\hline $\begin{array}{l}\text { Compression Set } \\
22 \mathrm{~h} \text { at } 70^{\circ} \mathrm{C} \\
22 \mathrm{~h} \text { at } 23^{\circ} \mathrm{C}\end{array}$ & ASTM D 395 "B" & $\begin{array}{l}\% \text { of original } \\
\text { deflection }\end{array}$ & $\begin{array}{l}45 \\
25\end{array}$ \\
\hline Glass Transition temperature* & BASF Analytical Method & ${ }^{\circ} \mathrm{C}$ & -35 \\
\hline Vicat Softening Temperature & ASTM D 1525 & ${ }^{\circ} \mathrm{C}$ & 120 \\
\hline DMA Softening Temperature & BASF Analytical Method & ${ }^{\circ} \mathrm{C}$ & 100 \\
\hline
\end{tabular}

